UNIVERSITA
DEGLISTUDI
DI TORINO

\title{
SCALE AND (QUASI) SCOPE ECONOMIES IN AIRPORT TECHNOLOGY: AN APPLICATION TO UK AIRPORTS
}

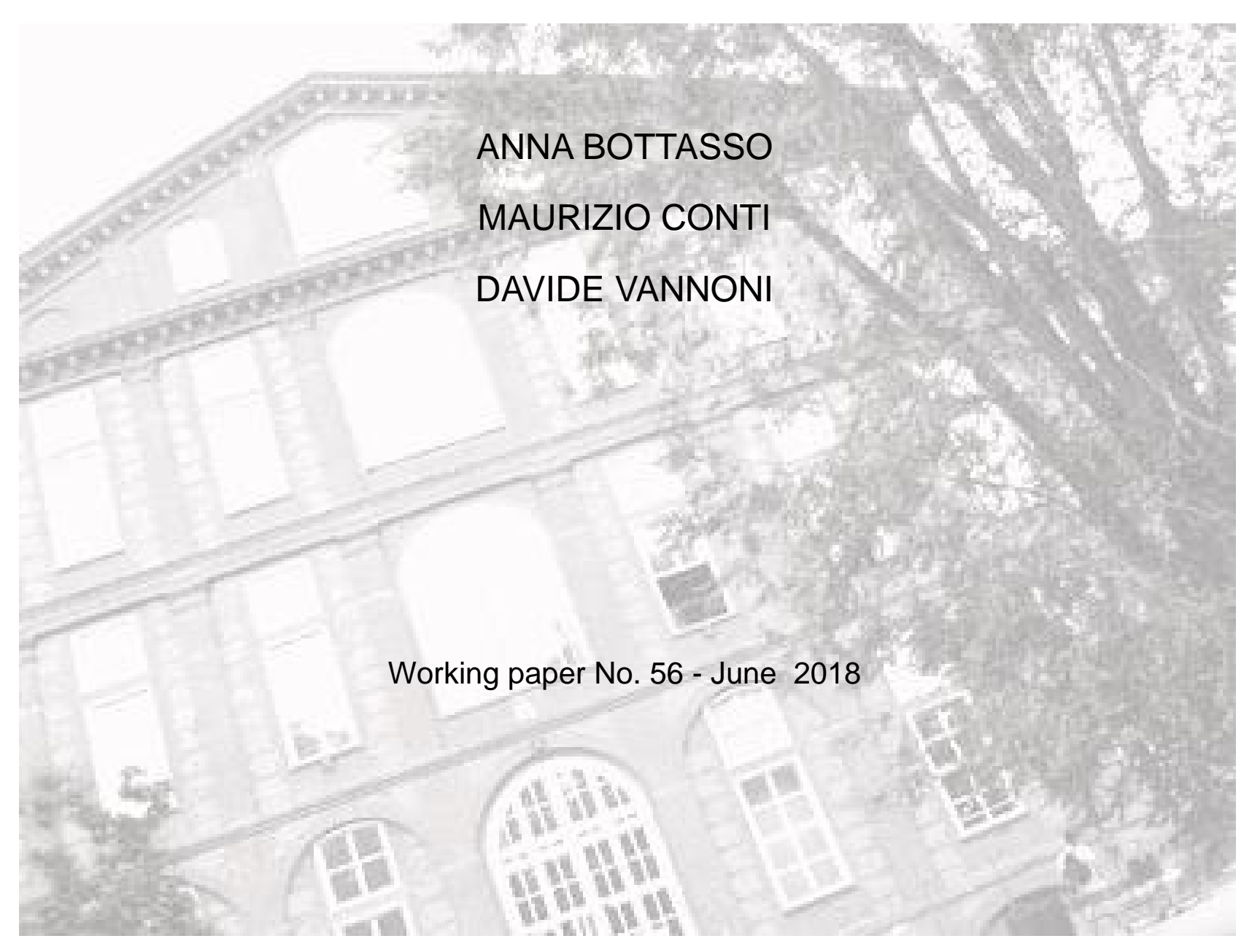




\title{
SCALE AND (QUASI) SCOPE ECONOMIES IN AIRPORT TECHNOLOGY AN APPliCATION To UK AIRPORTS
}

\author{
Anna Bottasso $^{\mathrm{a}}$, Maurizio Conti ${ }^{\mathrm{a}}$, Davide Vannoni ${ }^{\mathrm{b}, \mathrm{c}}$
}

\begin{abstract}
In this study we consider a sample of the largest UK airports in order to estimate, for the first time for this sector, a multiproduct cost function using a flexible technology that nests most of the specifications commonly employed in the empirical literature. Another novelty of this work is that we provide estimates of (quasi) scope economies for the airport industry. Our main results suggest the existence of (quasi) scope economies that tend to decline with the size of the airport. The finding on quasi scope economies coupled with a set of cost complementarity tests suggest that cost savings mainly arise from the joint provision of services for national and international passengers and, to a lesser extent, to the addition of cargo transport activities; in turn, the production of non aeronautical services seems to be characterized by anti-cost complementarities. Finally, we confirm previous findings in the literature that global economies of scale are exhausted at about five million passengers in the case of the UK airport industry.
\end{abstract}

Keywords: Scope and Scale Economies, Composite Cost Function, Airports.

JEL Code: L93, L23, C3.

${ }^{a}$ Department of Economics, University of Genoa, Via Vivaldi 5, 16126 Genova, Italy

${ }^{\mathrm{b}}$ Department of Economics, Mathematics and Statistics, University of Turin, Corso Unione Sovietica 218bis, 10134 Torino, Italy

${ }^{\mathrm{c}}$ Collegio Carlo Alberto, Piazza Vincenzo Arbarello 8, 10122 Torino, Italy

Corresponding Author: Davide Vannoni, Department of Economics, Mathematics and Statistics, University of Turin, Corso Unione Sovietica 218bis, 10134 Torino, Italy. Phone: +39-(0)11-6706083. davide.vannoni@unito.it 


\section{Introduction}

Recent studies in urban and regional economics have highlighted the positive effects that the aviation sector might play on the performance of local economies. ${ }^{1}$ Within the aviation industry, airports provide key essential facilities to airlines, such as runaways for landing and take-offs, parking space for aircrafts, check-indesks (and commercial services) for passengers, logistic services for the movements of cargo, among others. Possible inefficient provision of airport services might be transferred, through higher airport charges, to the downstream airline market and therefore to final customers, possibly jeopardising the abovementioned positive effects on local economic performance.

In the past few years, a rich empirical literature ${ }^{2}$ has sought to better understand and critically evaluate the main drivers of airports' efficiency and productivity dynamics, such as the type of ownership, the existence of economic regulation, the levels of corruption, the intensity of competition among airports and the role played by Low Cost Carriers. While this literature has enriched our knowledge of the determinants of efficiency and productivity differentials in the airport industry, our understanding of the cost structure of the sector, in terms of degree of scale economies, optimal output mix and economies of scope is still limited. This is unfortunate, because the optimal dimension of an airport, in terms of both scale and output mix, can have important implications as far as it concerns the overall minimization of the industry production costs. This is particularly true for an industry in which public ownership is still widespread, and where the opening of new airports is often justified as a place-based policy tool, with virtual no considerations paid to the possibility that demand might not allow the new airport to reach the minimum efficient scale and that global industry costs might even increase, as a result of the entry of the new operator.

If one looks at the empirical literature on the cost structure of the airport industry, recently surveyed by Bottasso and Conti (2017), it emerges that scale economies

\footnotetext{
${ }^{1}$ See, among others, Bloningen and Cristea (2015), Bilotkach (2015), Fageda (2017) and Gibbons and $\mathrm{Wu}(2017)$.

${ }^{2}$ See Bottasso et al. (2013), Bottasso et al. (2018), Martini et al. (2013), Yan and Oum (2014) and the literature review in Liebert and Niemeier (2013).
} 
are clearly important for small-to-medium sized airports, while there is still debate on whether or not the largest airport operators are enjoying economies of scale. Moreover, modern airports are multi-product firms, serving different types of passengers (e.g. domestic versus international), providing cargo and nonaeronautical services: a better understanding of the cost structure of the airport industry cannot avoid the evaluation of economies of scope; unfortunately, the evidence in this case is almost non-existent.

In this study we consider a sample of the 24 largest UK airport operators observed over the 1994-2008 period $^{3}$, and we estimate a multiproduct cost function using the Pulley and Braunstein (1992) flexible functional form, that nests most of the specifications commonly employed in the empirical literature and that we find to be superior, on statistical grounds, to both the generalized translog and the generalized quadratic. Our main findings are that global scale economies are exhausted for airports serving approximately 5 million passengers and that quasiscope economies - the relevant concept to consider when there are very few specialized airports in the sample - exist and decline with the size of the airport. For instance, quasi-scope economies might be as large as $60-70 \%$ in the case of airports serving 0.5 million passengers per year and $10-13 \%$ for airports serving about 9 million passengers. Interestingly, we also find that scope economies mainly arise through the combination of international and domestic passengers.

The remainder of this study is organized as follows. Section 2 surveys the relevant empirical literature, while Section 3 describes the econometric cost function model. Section 4 describes the data while Section 5 contains the estimation and model selection procedure. Finally, Section 6 describes the empirical results and Section 7 concludes.

\section{Literature review}

As highlighted in the recent survey conducted by Bottasso and Conti (2017), the available evidence on the presence of scope economies for airports is very scant.

\footnotetext{
${ }^{3}$ For a short summary of the main institutional and regulatory features of the UK airport industry, see Bottasso et al (2018).
} 
While very few papers tried to say something about cost complementarities between output pairs (which are a sufficient but not a necessary condition for the presence of scope economies), to the best of our knowledge, no one has attempted to undertake a direct estimation of aggregate scope economies, as well as scope economies for different output combinations and at different airport sizes, as yet.

McCarthy (2016) estimates a three output (number of departures - atm, commercial revenues and work load units- $w l u$, which include both the number of passengers and the amount of cargo transported) cost function for a sample of 50 US airports observed for the period 1996-2008. They find some evidence of anticost complementarities between non aeronautical revenues and wlu and between non aeronautical revenues and atm, while they suggests the presence of cost complementarities between aviation activities (wlu-atm), albeit the relation is not statistically significant. While these results could be consistent with the presence of diseconomies of scope, he recognizes that "Generalizing the model's variables through Box-Cox specifications which admit 0 outputs would enable the calculation of product-specific economies and economies of scope" (McCarthy, 2016, p. 272), a task which is left for future research. Abrate and Erbetta (2010) estimate a three output (number of passengers, handling revenues, and commercial revenues) input distance function for a sample of 26 Italian airports observed over the 2000-2005 period, and find evidence of anticomplementarities between passengers and handling revenues, especially when handling is outsourced. ${ }^{4}$ Chow and Fung (2009), working on a sample of 46 Chinese airports in 2000, estimate an input distance function using air passengers movements and air cargo movements as outputs, finding some evidence of cost complementarities between them. Finally, Martin and Voltes-Dorta (2011) estimate a cost function for a sample of 161 airports worldwide observed over the period 1991-1997, using five output categories (domestic and international passengers, an adjusted measure of atm, cargo and commercial revenues), and find evidence of cost complementarities only between domestic and international passengers.

As will be argued in section 4, the inclusion of outputs such as atm and wlu is not appropriate if the goal is to investigate the presence of scope economies. In fact,

4 When handling services are provided in-house, instead, they find evidence of cost complementarities. 
since atm accounts for the number of flights, and wlu includes the number of national and international passengers as well as freight transportation, it is clear that they are highly correlated and cannot be interpreted as distinct (but potentially interdependent) activities, as required for a correct investigation of scope economies. For that reason, in this paper we consider four categories of outputs that, at least in principle, could be present or not in an airport: domestic passengers, international passengers, commercial revenues and cargo transport. Our dataset reveals that there are very few instances of "zero outputs", because all UK airports are offering domestic and international flights, and at the same time they all provide cargo transport and undertake commercial activities. Therefore, while it is possible to compute cost complementarities, the computation of scope economies would not be appropriate, as it would involve out of the sample evaluations with output mixes that are very different from what it is actually observed in UK airports (an issue known as extrapolations bias) ${ }^{5}$. As an alternative, we will rely on the concept of "quasi"-scope economies where, instead of setting zero values for some outputs, firms are assumed to produce a small positive amount of each output, and we will compare the costs of quasispecialized airports (i.e. focusing mostly, but not completely, in cargo transport, or in international flights, or in national flights, or in commercial activities) with the costs of diversified airports.

\section{The econometric cost function model}

The availability of data on costs, outputs and inputs for UK airports allows us to undertake a detailed study of the cost function ${ }^{6}$ in order to detect the presence of economies of scale and scope. According to the well-known Generalized Translog (GT) Specification (Caves et al., 1980), the cost function is given by:

\footnotetext{
${ }^{5}$ For a detailed discussion, see Bottasso and Conti (2017).

${ }^{6} \mathrm{We}$ consider a total cost function. Alternatively, one might estimate a variable cost function, as in Bottasso and Conti (2012), which requires the assumption that firms minimize variable costs only. While this assumption is likely to be more defendable than total cost minimization, scope economies are usually estimated in a total cost function framework. Moreover, the results on scale economies in this study are very much in line with those of Bottasso and Conti (2012) who estimate a variable cost function for essentially the same sample and period.
} 


$$
\begin{aligned}
\ln C= & \alpha_{0}+\sum_{i} \alpha_{i} Y_{i}^{(\pi)}+\frac{1}{2} \sum_{i} \sum_{j} \alpha_{i j} Y_{i}^{(\pi)} Y_{j}^{(\pi)}+\sum_{i} \sum_{r} \delta_{i r} Y_{i}^{(\pi)} \ln P_{r} \\
& +\sum_{r} \beta_{r} \ln P_{r}+\frac{1}{2} \sum_{r} \sum_{l} \beta_{r l} \ln P_{r} \ln P_{l}+\psi_{C}
\end{aligned}
$$

where the superscripts in parentheses represent the Box-Cox transformation of outputs $\left(Y_{i}^{(\pi)}=\left(Y_{i}^{\pi}-1\right) / \pi\right.$ for $\pi \neq 0$ and $Y_{i}^{(\pi)} \rightarrow \ln Y_{i}$ for $\left.\pi \rightarrow 0\right)$. $C$ refers to the total cost of production, $Y_{i}$ refers to outputs (in our four-output case $i, j=P_{N A T}$, $P_{I N T}, C A R G O, R E V$ ), $P_{r}$ indicates factor prices (in our three-input case $r, l=L, K$, $O$ ), and $\psi_{C}$ is a random noise having appropriate distributional properties to reflect the stochastic structure of the cost model.

The associated input cost-share equations are obtained by applying the Shephard's Lemma to expression $[1]^{7}$

$$
S_{r}=\sum_{i} \delta_{i r} Y_{i}^{(\pi)}+\beta_{r}+\sum_{l} \beta_{r l} \ln P_{l}+\psi_{r}
$$

where $\psi_{r}$ is the error term relating to the cost-share $r$.

Setting $\pi \rightarrow 0$ in [1] and [2] yields the nested Standard Translog (ST) Specification, with all output terms in the cost function and in the corresponding cost-share equations assuming the usual logarithmic $\left(\ln Y_{i}\right)$ form. ${ }^{8}$

For small values of $\pi$, the estimated GT function is a close approximation to the ST functional form. Due to its log-additive output structure, the latter suffers from the well-known inability to evaluate cost behavior when any output is zero. This has been proved to yield unreasonable and/or very unstable values of the estimates for scope economies and product-specific scale economies (e.g., Pulley and Braunstein, 1992; McKillop et al., 1996).

To overcome the above problems, Pulley and Braunstein (1992) proposed a novel functional form - the Composite cost function -which is well suited for examining cost properties of multi-product firms. Such a model, as well as other widely used alternative cost functions, are nested into the following General specification $\left(\mathrm{PBG}_{\mathrm{G}}\right)$

\footnotetext{
${ }^{7}$ Cost-shares are computed as $S_{r}=\left(X_{r} P_{r}\right) / C$. By Shephard's Lemma $X_{r}=\partial C / \partial P_{r}$, where $X_{r}$ is the input demand for the $r$ th input, so that $S_{r}=\partial \ln C / \partial \ln P_{r}$.

${ }^{8}$ In this case zero values for any of the four outputs are substituted by 0.000001 .
} 


$$
\begin{aligned}
C^{(\phi)}= & \left\{\exp \left[\left(\alpha_{0}+\sum_{i} \alpha_{i} Y_{i}^{(\pi)}+\frac{1}{2} \sum_{i} \sum_{j} \alpha_{i j} Y_{i}^{(\pi)} Y_{j}^{(\pi)}+\sum_{i} \sum_{r} \delta_{i r} Y_{i}^{(\pi)} \ln P_{r}\right)^{(\tau)}\right]\right. \\
& \left.\cdot \exp \left[\sum_{r} \beta_{r} \ln P_{r}+\frac{1}{2} \sum_{r} \sum_{l} \beta_{r l} \ln P_{r} \ln P_{l}\right]\right\}^{(\phi)} \\
S_{r}= & \left(\sum_{i} \delta_{i r} Y_{i}^{(\pi)}\right) \cdot\left[\alpha_{0}+\sum_{i} \alpha_{i} Y_{i}^{(\pi)}+\frac{1}{2} \sum_{i} \sum_{j} \alpha_{i j} Y_{i}^{(\pi)} Y_{j}^{(\pi)}+\sum_{i} \sum_{r} \delta_{i r} Y_{i}^{(\pi)} \ln P_{r}\right]^{\tau-1} \\
& +\beta_{r}+\sum_{l} \beta_{r l} \ln P_{l}
\end{aligned}
$$

where the superscripts in parentheses $\pi, \phi$ and $\tau$ represent Box-Cox transformations.

The composite specification $\left(\mathrm{PB}_{\mathrm{C}}\right)$ is obtained by setting $\pi=1$ and $\tau=0$. In a similar vein, the well-known Generalized Translog (GT) and Standard Translog (ST) models, as well as a Separable Quadratic (SQ) functional form can be estimated by imposing simple restrictions on the system (1)-(2). ${ }^{9}$

The PB cost functions originate from the combination of the log-quadratic input price structure of the ST and GT specifications with a quadratic structure for outputs. The latter is appropriate to model cost behaviour in the range of zero output levels and gives the PB specifications an advantage over the ST and GT forms as far as the measurement of economies of scope is concerned. In addition, the log-quadratic input price structure can be easily constrained to be linearly homogeneous. ${ }^{10}$

The studies that made use of the PB specification in order to study economies of scale and scope are still few. After the first applications to the banking industry (Pulley and Braunstein, 1992; Pulley and Humphrey, 1993; McKillop et al., 1996) and telecommunications (Braunstein and Pulley, 1998; Bloch et al., 2001; McKenzie and Small, 1997), the Composite specification has been used to study the cost function of local public utilities providing services such as water,

\footnotetext{
${ }^{9}$ More precisely, the GT model is obtained by setting $\phi=0$ and $\tau=1$, while the ST model requires the further restriction $\pi=0$. The SQ model is obtained from the $\mathrm{PB}_{\mathrm{C}}$ specification by adding the restrictions $\delta_{i r}=0$ for all $i$ and $r$.

${ }^{10}$ To be consistent with cost minimization, (1) must satisfy symmetry $\left(\alpha_{i j}=\alpha_{j i}\right.$ and $\beta_{r l}=\beta_{l r}$ for all couples $i, j$ and $r, l)$ as well as the following properties: $a$ ) non-negative fitted costs; $b$ ) nonnegative fitted marginal costs with respect to outputs; $c$ ) homogeneity of degree one of the cost function in input prices $\left(\Sigma_{r} \beta_{r}=1\right.$ and $\Sigma_{l} \beta_{r l}=0$ for all $r$, and $\Sigma_{r} \delta_{i r}=0$ for all $\left.\left.i\right) ; d\right)$ non-decreasing fitted costs in input prices; $e$ ) concavity of the cost function in input prices.
} 
electricity, and gas distribution (Piacenza and Vannoni, 2004; Bottasso et al., 2011), garbage collection (Abrate et al., 2014), as well as public transportation (Di Giacomo and Ottoz, 2010; Ottoz and Di Giacomo, 2012; Abrate et al., 2016). Overall, the composite model proved to be successful in obtaining more stable and reliable estimates than the alternative functional forms. To the best of our knowledge, this is the first application to the airport technology.

\subsection{Measures of scale and scope economies}

Assume the multi-product cost function to be represented by $C=C(Y ; P)$, where $Y=\left(Y_{P N A T}, Y_{P I N T}, Y_{C A R G O}, Y_{R E V}\right)$ and $P=\left(P_{L}, P_{K}, P_{O}\right)$. Following Baumol et al. (1982), measures of global scale and scope economies can be easily defined. Global or aggregate scale economies are computed via

$$
S L(Y ; P)=\frac{C(Y ; P)}{\sum_{i} Y_{i} M C_{i}}=\frac{1}{\sum_{i} \varepsilon_{C Y_{i}}}
$$

Where $M C_{i}=\partial C(Y ; P) / \partial Y_{i}$ is the marginal cost of the $i$ th output and $\varepsilon_{C Y_{i}}=\partial \ln C(Y ; P) / \partial \ln Y_{i}$ is the cost elasticity with respect to the $i$ th output.

The above measure describes the behavior of costs as all outputs increase by strictly the same proportion.

The second relevant cost economy measure that is relevant for the comprehension of the cost structure of multi-product firms is that of scope economies. The latter appear when the cost of joint production of a given output set is lower than the sum of the "stand-alone" production costs of subsets of outputs. In other words, scope economies (diseconomies) are reflected into cost savings (cost disadvantages) associated with the joint production of many outputs. When there are neither economies nor diseconomies of scope the production process is said to be non-joint, so that productive inputs are completely specialized by product and there are no strong interdependencies among the costs of different outputs. The measure of global or aggregate scope economies for our airports could be computed via 
$S C(Y ; P)=\frac{\left[C\left(Y_{P N A T}, 0,0,0 ; P\right)+C\left(0, Y_{P I N T}, 0,0 ; P\right)+C\left(0,0, Y_{C A R G O}, 0 ; P\right)+C\left(0,0,0, Y_{R E V} ; P\right)-C(Y ; P)\right]}{C(Y ; P)}$ [6]

with $S C(Y ; P)>0(<0)$ denoting global economies (diseconomies) of scope.

A partial indication of the synergies that could be enjoyed by combining the production of several goods (or the provision of different services) comes from cost complementarity tests. Cost complementarities exist in a multi-product cost function when the marginal cost of producing one product $\left(Y_{i}\right)$ decreases as the quantity of another output $\left(Y_{j}\right)$ is increased. More formally, for a twice continuously differentiable cost function, cost complementarities are present at $Y^{\prime}$ if

$$
C C_{i j}\left(Y^{\prime} ; P\right)=\frac{\partial^{2} C\left(Y^{\prime} ; P\right)}{\partial Y_{i} \partial Y_{j}}<0, \quad i \neq j
$$

for all $Y^{\prime} \in[0, Y]$.

Cost complementarity tests can be applied only to pairs of outputs. While they are informative, they do not offer conclusive information about the presence of scope economies. Scope economies can be due to the sharing of fixed costs among different activities, even in the presence of cost anti-complementarities. ${ }^{11}$

However, differently from multi-utilities, jointly providing services (gas, water, electricity) that could be offered also by specialized firms, or from diversified bus companies (providing intercity and urban passenger transport services) that coexist together with specialized urban or intercity operators, or from waste management companies, that could be diversified into recycling activities or not, all airports are expected to provide international and domestic flights, together with cargo transport services, and are generally managing other activities that generate commercial revenues. Indeed, in our dataset, we have only few "zeros" for cargo activities (two observations) and for international flights (two observations). In such a context, it is not appropriate to estimate scope economies using equation [6], and this difficulty might explain why the literature has been practically silent with respect to the issue of scope economies, and only

\footnotetext{
${ }^{11}$ In other terms, the concept of scope economies is related to the firm's total costs and not to the marginal cost of each single output. Baumol et al. (1982) have shown that a multi-product cost
} 
sporadically has provided some estimates of cost complementarities between pairs of outputs/services.

A concept that can be fruitfully used in this case is that of "quasi"-scope economies where, instead of setting $Y_{i}=0$, firms are assumed to produce a small positive share of the median output $\left(\varepsilon Y_{i}\right)$. The general formula for "quasi"-scope economies in our four-outputs case is

$Q S C(\varepsilon)=\left[C\left(\varepsilon Y_{P N A T}, \varepsilon Y_{P I N T}, \varepsilon Y_{C A R G O},(1-3 \varepsilon) Y_{R E V}\right)+C\left(\varepsilon Y_{P N A T}, \varepsilon Y_{P I N T},(1-3 \varepsilon) Y_{C A R G O}\right.\right.$, $\left.\varepsilon Y_{R E V}\right)+C\left(\varepsilon Y_{P N A T},(1-3 \varepsilon) Y_{P I N T}, \varepsilon Y_{C A R G O}, \varepsilon Y_{R E V}\right)+C\left((1-3 \varepsilon) Y_{P N A T}, \varepsilon Y_{P I N T}, \varepsilon Y_{C A R G O}\right.$, $\left.\left.\varepsilon Y_{R E V}\right)-C\left(Y_{P N A T}, Y_{P I N T}, Y_{C A R G O}, Y_{R E V}\right)\right] / C\left(Y_{P N A T}, Y_{P I N T}, Y_{C A R G O}, Y_{R E V}\right)$

Surprisingly enough, notwithstanding the computation of $Q S C(\varepsilon)$ is appealing in circumstances in which firms are expected to manufacture several outputs (or to provide several services) at different combinations, but specialized units are not plausible, only few papers investigated them (Pulley and Humphrey, 1993; Di Giacomo and Ottoz, 2010, Delgado et al., 2015).

\section{Data description}

Our dataset refers to a balanced panel of $24 \mathrm{UK}$ airports observed over the period 1994-2008, for a total of 360 pooled observations.

Total cost $(C)$ is the sum of labor cost and other factors costs, including energy, materials, services and depreciation. The four output categories are: yearly number of national passengers $\left(Y_{P N A T}\right)$, yearly number of international passengers $\left(Y_{P I N T}\right)$, tons of cargo\&mail $\left(Y_{C A R G O}\right)$, commercial revenues $\left(Y_{R E V}\right)$ (i.e., revenues different from charges to airlines companies, coming from retail and property, car parking, baggage handling, apron services, hangar, etc.). ${ }^{12}$

Productive factors are labor, capital and other factors. The price of labor $\left(P_{L}\right)$ is given by yearly average of the weekly average salary in the area in which the airport is located. The price of capital $\left(P_{K}\right)$ is a proxy of the user cost of capital, measured by the opportunity cost of capital and a depreciation rate of 0.045 , common for all airports. Finally, the price of other factors $\left(P_{O}\right)$ is obtained as a

function characterized by weak cost complementarities over the full set of outputs up to the observed level of output exhibits scope economies.

${ }^{12}$ As argued in section 2, we believe that the use of output measures such as atm and/or wlu is not appropriate if the aim is to investigate the presence of scope economies. 
weighted average of the Construction Output Price Index (COPI), a proxy for material prices, a price index for water, gas and electricity, and the Retail Price Index (RPI), a proxy for other services purchased by airports, where the weights are taken from various years of BAA's statutory accounts. Summary statistics are provided in Table 1.

Figure 1 shows the distribution of the four outputs for the 24 UK airports, classified in four size groups according to the average level of total costs over the period 1994-2008. The height of each bar represents the size of an airport's output with respect to the average amount of that output in the total sample. For example, Heathrow, the largest airport in our dataset, serves a number of national passengers twice as large as the number of national passengers served by the average airport in the sample. The figure shows that there are airports which are relatively specialized in cargo activities (Nottingham East Midlands), in national flights (Cardiff, Exeter, Newcastle, Glasgow, Aberdeen, Edinburgh) or in international flights (London City), while other airports are diversified in national and international flights as well as in cargo activities (Liverpool, Leeds, Gatwick, Stanstead). Most importantly, the figures shows that there are not fully specialized airports. In fact, few "zeros" are recorded for cargo activities and for international passengers in some years, while for the large majority of observations all the 24 airports are simultaneously providing international and national flights, cargo services and are enjoying commercial revenues.

\section{Estimation procedure and model selection}

All the specifications of the multi-product cost function are estimated jointly with their associated input cost-share equations. ${ }^{13}$ Because the three share equations sum to unity, to avoid singularity of the covariance matrix only the labor $\left(S_{L}\right)$ and the capital share $\left(S_{K}\right)$ equations have been included in the systems. Before the estimation, all variables were standardized on their respective sample medians. Parameter estimates were obtained via a non-linear GLS estimation (NLSUR), which is the non-linear counterpart of the Zellner's iterated seemingly unrelated regression technique. This procedure ensures estimated coefficients to be invariant 
with respect to the omitted share equation (Zellner, 1962). Assuming the error terms in the above models are normally distributed, the concentrated loglikelihood for the estimated cost function and related labor-share and capitalshare equations can be respectively computed via ${ }^{14}$

$$
\begin{aligned}
& \ln L_{C}=-\sum_{t=1}^{T} \ln C_{t}-\frac{T}{2}[1+\ln (2 \pi)]-\frac{T}{2} \ln \left[\frac{1}{T} \sum_{t=1}^{T} \hat{\psi}_{C t}^{2}\right] \\
& \ln L_{S_{L}}=-\frac{T}{2}[1+\ln (2 \pi)]-\frac{T}{2} \ln \left[\frac{1}{T} \sum_{t=1}^{T} \hat{\psi}_{L t}^{2}\right] \\
& \ln L_{S_{K}}=-\frac{T}{2}[1+\ln (2 \pi)]-\frac{T}{2} \ln \left[\frac{1}{T} \sum_{t=1}^{T} \hat{\psi}_{K t}^{2}\right]
\end{aligned}
$$

where $t$ is the single observation $(t=1, \ldots, 360), \hat{\psi}_{C}, \hat{\psi}_{L}$ and $\hat{\psi}_{K}$ are the estimated residuals of the three regressions, and $\left(-\Sigma_{t} \ln C_{t}\right)$ is the logarithm of the Jacobian of the transformation of the dependent variable from $C_{t}$ to $\ln C_{t}\left(J=\prod_{t=1}^{T} J_{t}\right.$ with $\left.J_{t}=\left|\partial \psi_{C t} / \partial C_{t}\right|=1 / C_{t}\right)$. Similarly, the concentrated system log-likelihood is defined by:

$$
\ln L_{\left(C, S_{L}, S_{K}\right)}=\ln J-\frac{T}{2}[3(1+\ln (2 \pi))+\ln |\Omega|]
$$

where $J$ is the Jacobian of the transformation of $\left(C_{t}, S_{L t}, S_{K t}\right)$ to $\left(\ln C_{t}, S_{L t}, S_{K t}\right)$, and $\Omega$ is the $(3 \times 3)$ matrix of residual sum of squares and cross products for the system, with the $p q^{\text {th }}$ element of $\Omega, \Omega_{p q}$, equal to $\frac{1}{T} \sum_{t=1}^{T} \hat{\psi}_{p_{t}} \hat{\psi}_{q_{t}}$ and $p, q=C, S_{L}, S_{K}$. The summary results of the NLSUR estimations for the ST, GT, SQ, and PB models are presented in Table 2. In the first three rows, one can observe that the values of the Box-Cox parameters $\phi$ and $\pi$ are significant, while the coefficient associated to $\tau$ is not statistically different from zero. This gives a preliminary indication that Composite and quadratic models (which both assume $\tau=0$ )

\footnotetext{
${ }^{13}$ For the GT and PB models, for instance, this leads to the estimation of systems [1]-[2] and [3][4].

${ }^{14}$ See Greene (1997), Chapters 10 and 15.
} 
describe the data better than GT or Standard Translog models. The following five rows present the estimates of cost elasticities with respect to outputs and factor prices for the 'median' firm. ${ }^{15}$

While the five estimated cost function models seem to perform similarly with respect to labor price elasticity ( $S_{L}$ ranges from 0.21 to 0.26 and $S_{K}$ ranges from 0.39 to 0.41 ), the estimates for the output elasticities show a greater variability, with the $\mathrm{PB}_{\mathrm{G}}$ model attributing more weight to domestic passengers and less weight to commercial revenues.

By looking at the summary statistics, one can observe that the $R^{2}$ for the cost functions is very similar across models, while the $R^{2}$ for the labor-share equation ranges from 0.14 (SQ model) to 0.38 ( $\mathrm{PB}_{\mathrm{G}}$ model). The lower ability of the SQ specification to fit the observed factor-shares is not surprising given that it assumes a strong separability between inputs and outputs. McElroy's (1977) $R^{2}$ $\left(R_{*}^{2}\right)$ can be used as a measure of the goodness of fit for the NLSUR system. The results suggest that the fit is high for all five models.

Standard likelihood ratio (LR) hypothesis testing based on system log-likelihoods can be applied to see which model adjusts observed data better. The LR statistics are in favor of the $\mathrm{PB}_{\mathrm{G}}$ model, since all the alternative specifications are rejected (for example, comparing $\mathrm{PB}_{\mathrm{G}}$ with $\mathrm{PB}_{\mathrm{C}}$, the critical ${ }_{0.01} \chi_{(2)}^{2}=9.21$, while the computed $\chi_{(2)}^{2}=76.54$ ). Similarly, the null hypothesis that $\mathrm{PBC}$ and SQ (or GT and ST) models are equally close to the true data generating process is rejected in favor of the $\mathrm{PBC}_{\mathrm{C}}(\mathrm{GT})$.

Table 2 shows also the estimates of global economies of scale calculated for the median firm ( $\left.S L=1 / \sum \varepsilon_{C Y_{i}}\right)$. The results, which are not dramatically different across models (SL ranges from 1.05 to 1.18 and is always statistically different from 1), are clearly in favor of the presence of scale economies.

On the base of statistical fit, and as a result of LR based statistics, we therefore prefer to use the $\mathrm{PB}_{\mathrm{G}}$ specification for carrying out the empirical tests concerning quasi-scope and scale economies. ${ }^{16}$

${ }^{15}$ The median firm (the point of normalization) corresponds to a hypothetical firm operating at a median level of production for each output and facing median values of the input price variables.

${ }^{16}$ The estimated $\mathrm{PB}_{\mathrm{G}}$ cost function also satisfies each of the output and price regularity conditions at 90 percent of the sample data points. More precisely, fitted costs are always non-negative and 
Our results are robust to the inclusion of additional control variables such as a time trend (and its squared term), a dummy for regulated airports (Heathrow, Gatwick, Stanstead, Manchester), ownership dummies (private, public, mixed), and proxies for the role of low-cost carriers (the share of passengers or the share of flights managed by low-cost carriers). However, given that these variables often turned out to be insignificant ${ }^{17}$, we have dropped them from the final specification.

\section{Scale and "quasi" scope economies}

Table 3 reports in the last row the estimates of global scale economies evaluated

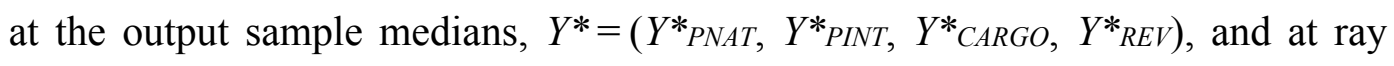
expansions and contractions of $Y^{*}$. More precisely, we consider the following output scaling: $\lambda Y^{*}=\left(\lambda Y^{*}{ }_{P N A T}, \lambda Y^{*}{ }_{P I N T}, \lambda Y^{*}{ }_{C A R G O}, \lambda Y^{*}{ }_{R E V}\right)$, with outputs ranging from one fourth $(\lambda=0.25)$ to four times $(\lambda=4)$ the values observed for the 'median' firm. All estimates are larger than one and significantly different from one (except for the case in which $\lambda=4$ ), and reveal the presence of increasing returns to scale for airports that serve up to about 5 million passengers. Economies of scale are quite large $(S L=1.5)$ for airports with a number of passengers below $500.000^{18}$, than they reduce progressively and appear to be exhausted for big airports, such as Heathrow, Gatwick, Stanstead, Manchester, Glasgow, Edinburgh, Birmingham and London Luton (which are all well above the threshold of 5 million passengers per year). Indeed, $S L$ becomes even lower than one, but the lack of statistical significance suggests caution in pointing towards the presence of diseconomies of scale for the largest UK airports. Such results are broadly in line with Bottasso and Conti (2012), even if they used a

non-decreasing in input prices (fitted factor-shares are positive at each observation). Concavity of the cost function in input prices is satisfied everywhere in the sample (the Hessian matrix based on the fitted factor-shares is negative semi-definite). Fitted marginal costs with respect to each output are non-negative for 341 observations on 360 .

${ }^{17}$ The only exception is the coefficient relative to private airports, which exhibited a positive sign, suggesting that public airports are characterized with lower costs. A similar result was found by Scotti et al. (2012) for Italian airports, even if the estimated model was a production frontier. Bottasso and Conti (2012) estimated a cost function for UK airports and found that private airports displayed lower costs during the 1994-2005 period, but the cost differential was disappearing across time, since public airports succeeded in cutting costs in the last years.

${ }^{18}$ Southend, Blackpool, Humberside, Norwich. 
different methodology and estimated a cost function which included a different set of outputs (atm, wlu, and commercial revenues).

Table 3 reports also the estimates of quasi-scope economies. In the central column, which focuses on the results for the "median airport", $Q S C(\varepsilon)$ is computed according to the formula in equation [8]. For example, in the fourth row $(\varepsilon=0.10)$ :

$Q S C(\varepsilon)=\left[C\left(0.1 * Y_{P N A T,} 0.1 * Y_{P I N T}, 0.1 * Y_{C A R G O}, 0.7 * Y_{R E V}\right)+C\left(0.1 * Y_{P N A T}, 0.1 * Y_{P I N T}\right.\right.$,

$\left.0.7 * Y_{C A R G O}, 0.1 * Y_{R E V}\right)+C\left(0.1 * Y_{P N A T,}, 0.7 * Y_{P I N T}, 0.1 * Y_{C A R G O}, 0.1 * Y_{R E V}\right)+$

$\left.C\left(0.7 * Y_{P N A T}, 0.1 * Y_{P I N T}, 0.1 * Y_{C A R G O}, 0.1 * Y_{R E V}\right)-C\left(Y_{P N A T}, Y_{P I N T}, Y_{C A R G O}, Y_{R E V}\right)\right] /$

$C\left(Y_{P N A T}, Y_{P I N T}, Y_{C A R G O}, Y_{R E V}\right)$

The positive estimate for $Q S C(\varepsilon)$ suggests that, by combining the production of four quasi specialized airports into a single airport (that would reach a size comparable to the median airport in our sample), costs would reduce by 18 percent. The other columns report the estimates of $Q S C(\lambda \varepsilon)$ for airports larger and lower than the sample median. ${ }^{19}$

The first row $(\varepsilon=0)$ reports the estimates of $S C$ according to the formula in equation [6], while the last row $(\varepsilon=0.25)$ de facto considers diversified airports that experience an increase in the size of all four activities. Therefore, as far as $\varepsilon$ gets closer to 0.25 , quasi scope economies, rather than being a useful proxy for scope economies, simply reflect the presence of global scale economies. ${ }^{20}$

Overall, the results are in favour of the presence of global (quasi) scope economies, which are very high for small airports (around 70\%) and reduce progressively as far as the size of the airport increases (when the passengers are close to 9 million per year, quasi scope economies are around $12 \%)$. When $\varepsilon$ is

19 Taking always the fourth row $(\varepsilon=0.10, \lambda=2)$ as an example: $\operatorname{QSC}_{(\lambda \varepsilon)}=\left[C\left(0.2 * Y_{P N A T}, 0.2 * Y_{P I N T}, 0.2 * Y_{C A R G O}, 1.4 * Y_{R E V}\right)+C\left(0.2 * Y_{P N A T}, 0.2 * Y_{P I N T}, 1.4 * Y_{C A R G O}, 0.2 * Y_{R}\right.\right.$ $\left.{ }_{E V}\right)+C\left(0.2 * Y_{P N A T}, 1.4 * Y_{P I N T}, 0.2 * Y_{C A R G O}, 0.2 * Y_{R E V}\right)+C\left(1.4 * Y_{P N A T}, 0.2 * Y_{P I N T}, 0.2 * Y_{C A R G O}, 0.2 * Y_{R E V}\right)-$ $\left.C\left(2 * Y_{P N A T}, 2 * Y_{P I N T}, 2 * Y_{C A R G O}, 2 * Y_{R E V}\right)\right] / C\left(2 * Y_{P N A T}, 2 * Y_{P I N T}, 2 * Y_{C A R G O}, 2 * Y_{R E V}\right)$. The value of 0.11 suggests that, combining the production of four relatively specialized airports into a diversified airport (that would be twice as big as the median airport in the sample), costs would reduce by 11 percent.

${ }^{20}$ Indeed, when $\varepsilon=0.25$ and $\lambda=1$, we compare the costs of four equally diversified airports (of a size equal to one fourth that of the median firm) with the costs of a single diversified airport of a size equal to the median firm. That is clearly a measure much more similar to $S L$ : in fact, after having subtracted one from the first three $S L$ figures (highlighted in italics and underlined) in the last row of Table 3, we get estimates which are not (and should not be) very different from the last three figures (highlighted in bold characters) in the seventh row (i.e., $1.349-1=0.349$, which is similar to 0.319 , and so on). 
very low (i.e, below 0.1) the figures are of a lower magnitude and lose statistical significance.

The analysis of cost complementarities $\left(C C_{i j} ; i, j=P_{N A T}, P_{I N T}, C A R G O, R E V\right.$, with $i \neq j$ ) provides further evidence on the cost advantage (or disadvantage) enjoyed by an airport which decides to diversify into different services. Under this empirical test, we investigate pairwise how an increase in the level of one of the four services will affect the marginal cost of producing the other ones. Unlike scope economies, cost complementarities are 'local' properties because they describe how the cost function behaves in the neighborhood of an observation or set of observations. Given the functional form of PB models, $C C_{i j}$ mostly depend on the second order cross-outputs coefficients, $\alpha_{i j}$, and on the input price levels. Table 4 reports the estimates of cost complementarities evaluated at the sample medians. The results show the presence of cost complementarities for the couples $P_{N A T-P I N T}$ and $P_{I N T}-C A R G O$, and anti-complementarities in all the couples involving $R E V$, while $C C_{P N A T, C A R G O}$ is not significantly different from zero. These findings suggest that offering flights for both international and national passengers would reduce the marginal costs of both services, while increasing the activities involving commercial revenues would result in an increase in the marginal cost of aviation activities (cargo, national and international flights). Bottasso and Conti (2017) interpret this finding as an indication that some airports might have devoted too much space to shops, at the expense of check-ins and gates, thereby creating congestion problems that impact negatively on aviation activities.

In spite of the fact that we use different output categories as well as a different methodology, our results are in line with McCarthy (2016), who found anticomplementarities between commercial revenues and aviation activities, and with Martin and Voltes-Dorta (2011), who found cost complementarities between domestic and international passengers.

In order to shade more light on the contribution of each of the four services in explaining the cost advantages of diversification, we compute quasi scope economies for different combinations of couples or "triplets" of outputs.

In fact, the quasi-scope economies estimates reported above refer to airports that, being quasi-specialized in one activity, diversify symmetrically in the other three services, and end up being fully diversified firms. We now analyze, more 
realistically, asymmetrical situations, such as airports that are mostly active in two services (for example, $P_{N A T}$ and $P_{I N T}$ ), or in three services, and consider a diversification in the remaining activities/activity. The results would be of help for airports that, being already diversified in an output pair (or in a "triplet" of services) are evaluating further diversification strategies.

Table 5 shows the estimates of $Q S C(\lambda=1, \varepsilon=0.1)$ for all the eight output pairs and the four output triplets. The results show that the average value of quasi-scope economies $(0.177)$ reported in Table 4 is essentially due to the synergies that can be exploited between $\mathrm{P}_{\mathrm{NAT}}$ and $\mathrm{P}_{\mathrm{INT}}$. Airports already diversified in national and international flights do not seem to obtain remarkable cost savings by increasing the activities in cargo transport and/or in commercial services ${ }^{21}$, while for airports with limited involvement in international (national) flights, an increase of YPNAT (Y PINT) would bring large cost benefits.

\section{Conclusions}

In this study we have estimated a total cost function for the UK airport industry using the Pulley and Braunstein (1992) flexible functional form. Our main findings are that scale economies are important only for airports up to about 5 million passengers, while larger airports tend to operate at approximately constant returns to scale. More interestingly, ours is the first paper to provide estimates for (quasi) scope economies in the airport industry, which we find to be large, although declining with size. Moreover, we find that (quasi) scope economies are largely associated to the synergies arising from the combination of international and domestic passengers; in turn, commercial services tend to increase the marginal costs of producing passengers and cargo services. However, it should be borne in mind that the anti-cost complementarity result for commercial activities should be traded-off with possible increases in revenues associated to the exploitation of airports spaces.

\footnotetext{
${ }^{21}$ While the effect of expanding cargo activities is small, but positive ( $Q S C$ PNAT-PINT-REV $=0.031$ ), the negative values reported for $Q S C$ PNAT-PINT and $Q S C$ PNAT-PINT-CARGO, albeit not significantly different from zero, are due to the presence of anti-complementarities between aviation activities and commercial revenues.
} 
The results of this study might be of interest to policymakers who a) need to undertake a cost benefit analysis to inform a decision on whether to open a small airport and b) need to decide whether to close an airport and concentrate the activity in a neighboring one (which might be producing different outputs). Moreover, our findings on quasi-scope economies might be important also for airport managers who might be planning to expand and/or diversify their airport's activities. 
Figure 1. Distribution of Outputs among UK Airports

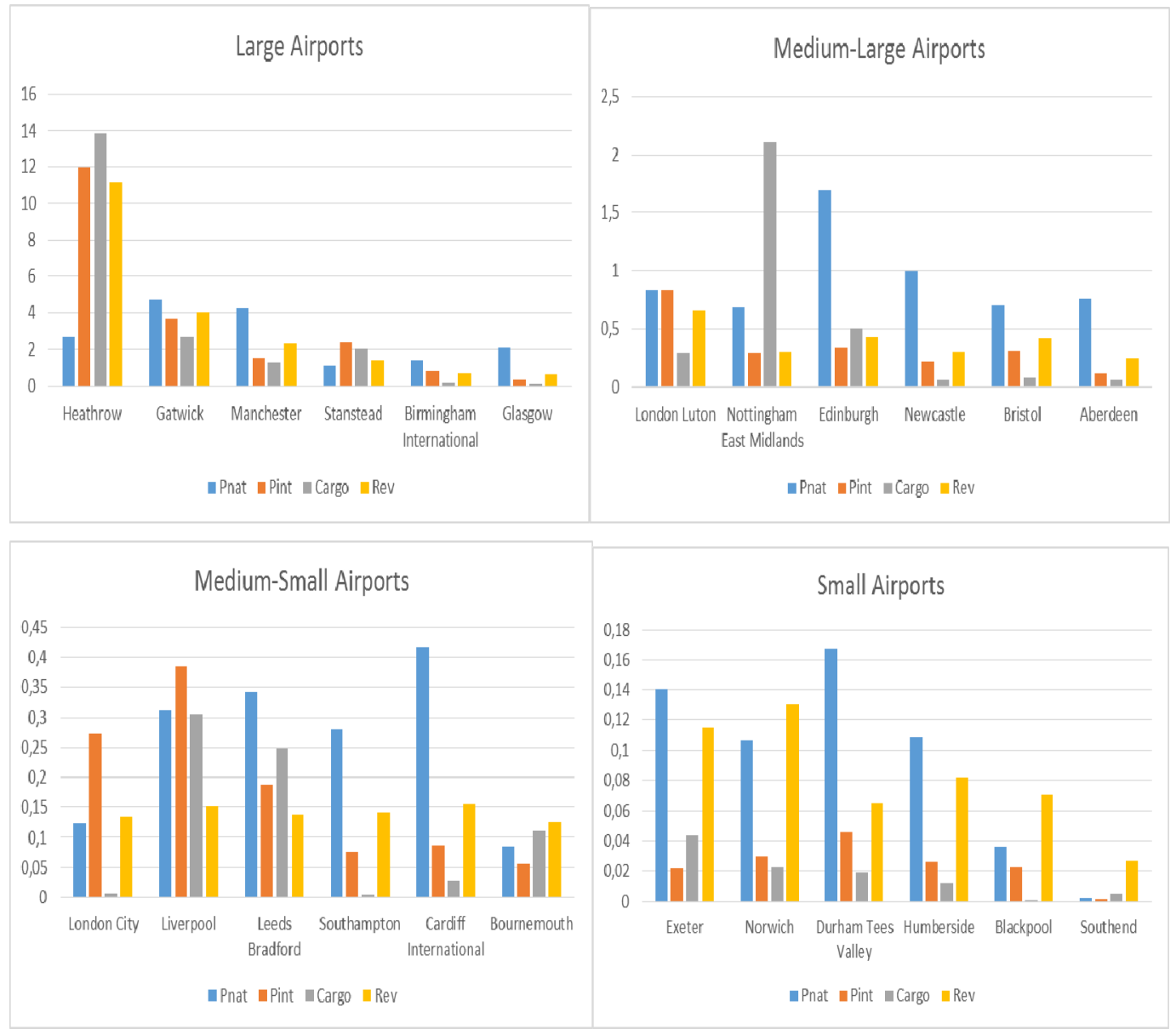

Table 1. Summary Statistics

\begin{tabular}{lrrrrr}
\hline & Mean & Std. dev. & Min & Median & Max \\
\cline { 2 - 6 } Total Cost $(000 £)$ & 98654 & 230314 & 2501 & 27468 & 2010315 \\
\hline \hline Output & & & & & \\
P $_{\text {NAT }}$ & 2822911 & 3600181 & 3457 & 1348300 & 14861000 \\
PINT $_{\text {CARGO (tons) }}$ & 4602617 & 11473984 & 0 & 667480 & 63253333 \\
REV (000£) & 94564 & 265561 & 0 & 7189 & 1486300 \\
\hline \hline Input prices & 63230 & 145993 & 929 & 13632 & 750280 \\
Price of labor (£) & & & & & \\
Price of capital (percentage) & 18808 & 3641 & 11526 & 18385 & 32374 \\
Price of other inputs (index) & 0.122 & 0.002 & 0.119 & 0.123 & 0.125 \\
\hline \hline Cost shares & 163 & 21 & 133 & 159 & 202 \\
Labor share & & & & & \\
Capital share & & & & & \\
Other inputs share & 0.263 & 0.095 & 0.016 & 0.249 & 0.550 \\
\hline
\end{tabular}





\begin{tabular}{|c|c|c|c|c|c|}
\hline & $\mathrm{PB}_{\mathrm{G}}$ MODEL & $\mathrm{PB}_{\mathrm{C}}$ MODEL & SQ MODEL & GT MODEL & ST MODEL \\
\hline \multicolumn{6}{|l|}{ Box-Cox Parameters } \\
\hline$\phi$ & $-0.0922 * * *(0.029)$ & $-0.0366(0.032)$ & $-0.0319(0.0288)$ & 0 & 0 \\
\hline$\pi$ & $0.7290 * * *(0.045)$ & 1 & 1 & $0.3377 * * *(0.0226)$ & 0 \\
\hline$\tau$ & $-0.0211 \quad(0.058)$ & 0 & 0 & 1 & 1 \\
\hline \multicolumn{6}{|c|}{ Output and factor prices elasticities $\mathrm{b}$} \\
\hline $\mathcal{E}_{C Y_{P N A T}}$ & $0.0878 * * *(0.0415)$ & $0.0451 * * *(0.0188)$ & $0.0511 * \quad(0.0299)$ & $0.0478^{*} \quad(0.0277)$ & $0.0564 * * \quad(0.0226)$ \\
\hline$\varepsilon_{C Y_{P I N T}}$ & $0.1716^{* *}(0.0538)$ & $0.1898 * * * \quad(0.0447)$ & $0.1797 * * *(0.0423)$ & $0.1754 * * *(0.0396)$ & $0.1383 * * *(0.0329)$ \\
\hline$\varepsilon_{C Y_{C I P C T}}$ & $0.1712 * * *(0.0438)$ & $0.1356 * * *(0.0383)$ & $0.1278 * * *(0.0360)$ & $0.1537 * * *(0.0340)$ & $0.1449 * * *(0.0304)$ \\
\hline$\varepsilon_{C Y}^{C Y_{C A R G O}}$ & $0.4188^{* * *}(0.0851)$ & $0.5568 * * *(0.0644)$ & $0.5697 * * *(0.6189)$ & $0.5741 * * *(0.0758)$ & $0.5539 * * *(0.0505)$ \\
\hline${ }^{C} Y_{R E V}$ & $0.2071 * * *(0.0101)$ & $0.2119 * * *(0.0104)$ & $0.2638 * * \quad(0.1185)$ & $0.2288 * * *(0.0096)$ & $0.2230 * * *(0.0107)$ \\
\hline $\begin{array}{l}S_{L} \\
S_{K}\end{array}$ & $0.4015^{* * *}(0.0101)$ & $0.4017 * * *(0.0106)$ & $0.3879 * * *(0.1246)$ & $0.4098 * * *(0.0114)$ & $0.4022 * * *(0.0115)$ \\
\hline Scale Economies: $1 /\left(\sum \varepsilon_{C Y_{i}}\right)$ & $1.1773^{* * *}(0.0036)$ & $1.0785^{* * *}(0.0267)$ & $1.0772 * * *(0.0229)$ & $1.0513 * * *(0.0035)$ & $1.1193 * * *(0.0228)$ \\
\hline System log-likelihood & 1248.31 & 1210.04 & 1106.10 & 1213.34 & 1169.72 \\
\hline Goodness of fit ${ }^{c}$ & 0.9979 & 0.9976 & 0.9974 & 0.9979 & 0.9974 \\
\hline Cost Function $\mathrm{R}^{2}$ & 0.9991 & 0.9990 & 0.9989 & 0.9991 & 0.9987 \\
\hline Labor share $\mathrm{R}^{2}$ & 0.3841 & 0.3667 & 0.1414 & 0.2956 & 0.2754 \\
\hline Capital share $\mathrm{R}^{2}$ & 0.3303 & 0.3312 & 0.0183 & 0.3256 & 0.2726 \\
\hline \multicolumn{6}{|l|}{ LR test statistics } \\
\hline $\mathrm{PB}_{\mathrm{G}}$ versus other models & -- & $76.54^{\mathrm{d}}$ & $284.42^{d}$ & $69.94^{\mathrm{d}}$ & $157.18^{\mathrm{d}}$ \\
\hline $\mathrm{PB}_{\mathrm{C}}$ versus $\mathrm{SQ}$ & -- & -- & $207.88^{d}$ & -- & -- \\
\hline GT versus ST & -- & -- & -- & -- & $87.24^{\mathrm{d}}$ \\
\hline
\end{tabular}

a Estimated asymptotic standard errors in parentheses computed using the 'delta' method (Greene, 1997). *** Significant at $1 \%,{ }^{* *}$ Significant at $5 \%, *$ Significant at $10 \%$.

${ }^{\mathrm{b}}$ The values are computed at the median firm.

c The goodness-of-fit measure for the NLSUR systems is McElroy's (1977) $R^{2}$.

${ }^{d}$ The null hypothesis that the two models fit equally well the data is rejected at the $1 \%$ level of significance. 
Table 3. Estimates of quasi-scope economies for the $P B_{G}$ model at different output levels (and at the medians of input price variables) ${ }^{a}$

\begin{tabular}{|c|c|c|c|c|c|}
\hline & $\begin{array}{c}\lambda=0.25 \\
(550,000 \\
\text { passengers })\end{array}$ & $\begin{array}{c}\lambda=0.5 \\
(1.1 \text { million } \\
\text { passengers })\end{array}$ & $\begin{array}{c}\lambda=1 \\
(2.2 \text { million } \\
\text { passengers })\end{array}$ & $\begin{array}{c}\lambda=2 \\
\text { (4.4 million } \\
\text { passengers) }\end{array}$ & $\begin{array}{c}\lambda=4 \\
\text { (8.8 million } \\
\text { passengers) }\end{array}$ \\
\hline $\begin{array}{l}\operatorname{QSC}(\varepsilon, \lambda): \text { Quasi-scope } \\
\text { economies }^{b}\end{array}$ & & & & & \\
\hline$\varepsilon=0$ (SL: Global scope economies) & $\begin{array}{c}0.391 \\
(0.924)\end{array}$ & $\begin{array}{c}0.146 \\
(1.202)\end{array}$ & $\begin{array}{c}0.010 \\
(1.664)\end{array}$ & $\begin{array}{l}-0.004 \\
(2.232)\end{array}$ & $\begin{array}{l}-0.033 \\
(2.823)\end{array}$ \\
\hline$\varepsilon=0.01$ & $\begin{array}{c}0.459 \\
(0.844)\end{array}$ & $\begin{array}{c}0.215 \\
(1.075)\end{array}$ & $\begin{array}{c}0.133 \\
(1.206)\end{array}$ & $\begin{array}{c}0.022 \\
(1.944)\end{array}$ & $\begin{array}{c}0.013 \\
(2.443)\end{array}$ \\
\hline$\varepsilon=0.05$ & $\begin{array}{c}0.566 \\
(0.652)\end{array}$ & $\begin{array}{c}0.319 \\
(0.764)\end{array}$ & $\begin{array}{c}0.151 \\
(0.818)\end{array}$ & $\begin{array}{c}0.104 \\
(0.813)\end{array}$ & $\begin{array}{c}0.122 \\
(0.815)\end{array}$ \\
\hline$\varepsilon=0.10$ & $\begin{array}{c}0.641 \\
(0.489)\end{array}$ & $\begin{array}{c}0.392 \\
(0.496)\end{array}$ & $\begin{array}{l}0.177 * * \\
(0.091)\end{array}$ & $\begin{array}{l}0.110^{*} \\
(0.062)\end{array}$ & $\begin{array}{l}0.107 * * \\
(0.051)\end{array}$ \\
\hline$\varepsilon=0.15$ & $\begin{array}{c}0.689 * \\
(0.387)\end{array}$ & $\begin{array}{l}0.438 * * \\
(0.222)\end{array}$ & $\begin{array}{l}0.145 * * * \\
(0.059)\end{array}$ & $\begin{array}{l}0.131 * * * \\
(0.049)\end{array}$ & $\begin{array}{l}0.118 * * * \\
(0.036)\end{array}$ \\
\hline$\varepsilon=0.20$ & $\begin{array}{l}0.719 * * \\
(0.333)\end{array}$ & $\begin{array}{l}0.467 * * \\
(0.236)\end{array}$ & $\begin{array}{l}0.249 * * * \\
(0.046)\end{array}$ & $\begin{array}{l}0.221 * * * \\
(0.056)\end{array}$ & $\begin{array}{l}0.112 * * * \\
(0.035)\end{array}$ \\
\hline$\varepsilon=0.25$ & $\begin{array}{l}0.768^{*} \\
(0.465)\end{array}$ & $\begin{array}{l}0.477 * * \\
(0.214)\end{array}$ & $\begin{array}{l}\text { 0.319*** } \\
(0.048)\end{array}$ & $\begin{array}{l}\mathbf{0 . 2 2 9} * * * \\
(0.045)\end{array}$ & $\begin{array}{l}\text { 0.129** } \\
(0.067)\end{array}$ \\
\hline SL: Global scale economies & $\frac{1.349}{(0.049)}$ & $\frac{1.252}{(0.036)}^{* * *}$ & $\underline{1.177}^{* * *}$ & $\begin{array}{l}1.098^{*} \\
(0.050)\end{array}$ & $\begin{array}{c}0.945 \\
(0.106)\end{array}$ \\
\hline
\end{tabular}

\footnotetext{
${ }^{a}$ Estimated asymptotic standard errors in parentheses. $* * *$ Significant at $1 \%, * *$ Significant at 5\%, * Significant at $10 \%$.

${ }^{b}$ Coefficient $\varepsilon \in[0,0.25]$ has been used to split the production of the four outputs among firms, so as to generate configurations ranging from four specialized firms $(\varepsilon=0.0)$ up to four diversified firms $(\varepsilon=$ $0.25)$. Parameter $\lambda$ refers to the coefficient used to scale down $(\lambda=0.25,0.5)$ and up $(\lambda=2,4)$ the median values of the four outputs.
} 
Table 4. Estimates of cost complementarities for the $P B_{G}$ model evaluated at the sample median outputs (at the median input prices)*

\begin{tabular}{cccccc}
\hline$C C_{P N A T, P I N T}$ & $C C_{P N A T, C A R G O}$ & $C C_{P I N T, C A R G O}$ & $C C_{P I N T, R E V}$ & $C_{C A R G O, R E V}$ & $C_{P N A T, R E V}$ \\
\hline \hline$-0.340^{* * *}$ & -0.001 & $-0.178^{* *}$ & $0.620^{* * *}$ & $0.264^{* *}$ & $0.388^{* * *}$ \\
$(0.084)$ & $(0.064)$ & $(0.092)$ & $(0.154)$ & $(0.119)$ & $(0.125)$ \\
\hline
\end{tabular}

* Estimated asymptotic standard errors in parentheses. *** Significant at 1\%, ** Significant at 5\%,* Significant at $10 \%$.

Table 5. Estimates of quasi-scope economies for airports quasi-specialized in "couples" of activities or diversified in "triplets" of activities for the $P B_{G}$ model evaluated at the sample median outputs (at the median input prices)*

\begin{tabular}{|c|c|c|c|c|c|c|}
\hline \multirow[b]{2}{*}{ COUPLES } & \multicolumn{6}{|c|}{$\operatorname{QSC}_{\text {COUPLE }}(\varepsilon=0.1, \lambda=1)$} \\
\hline & $\mathrm{P}_{\mathrm{NAT}}-\mathrm{CARGO}$ & $\mathrm{CARGO}_{\mathrm{REV}}^{\mathrm{P}_{\mathrm{NAT}}-\mathrm{P}_{\mathrm{INT}}}$ & $\mathrm{CARGO}_{\mathrm{P}_{\mathrm{INT}}}^{\mathrm{P}_{\mathrm{NAT}}-\mathrm{REV}}$ & $\underbrace{\mathrm{P}_{\mathrm{INT}}-\mathrm{CARGO}}_{\mathrm{P}_{\mathrm{NAT},} \mathrm{REV}}$ & CARGO-REV & $\mathrm{P}_{\mathrm{INT}}-\mathrm{REV}$ \\
\hline & $\begin{array}{c}0.079 * \\
(0.045)\end{array}$ & $\begin{array}{l}-0.101 \\
(0.062)\end{array}$ & $\begin{array}{l}0.191 * * \\
(0.092)\end{array}$ & $\begin{array}{l}0.042 * * \\
(0.026)\end{array}$ & $\begin{array}{l}0.262^{* * *} \\
(0.114)\end{array}$ & $\begin{array}{l}0.321 * * * \\
(0.119)\end{array}$ \\
\hline & \multicolumn{6}{|c|}{$\operatorname{QSCTRIPLET}_{(}(\varepsilon=0.1, \lambda=0.1)$} \\
\hline
\end{tabular}

\begin{tabular}{|c|c|c|c|c|}
\hline TRIPLETS & $\mathrm{P}_{\mathrm{NAT}}-\mathrm{P}_{\mathrm{INT}-\mathrm{CARGO}}$ & $\mathrm{P}_{\mathrm{NAT}}-\mathrm{P}_{\mathrm{INT}}-\mathrm{REV}$ & $\mathrm{P}_{\mathrm{NAT}}-\mathrm{CARGO}-\mathrm{REV}$ & $\mathrm{P}_{\mathrm{INT}-\mathrm{CARGO}-\mathrm{REV}}$ \\
\hline & -0.077 & $0.031^{*}$ & $0.217 * * *$ & $0.331 * * *$ \\
\hline & $(0.061)$ & $(0.019)$ & $(0.093)$ & $(0.041)$ \\
\hline
\end{tabular}

* Estimated asymptotic standard errors in parentheses. *** Significant at 1\%, ** Significant at 5\%, * Significant at $10 \%$.

QSC COUPLE $(\varepsilon=0.1)$, for a firm quasi-specialized in a generic pair of outputs $\left(\mathrm{Y}_{1}, \mathrm{Y}_{2}\right)$, is computed as $\left[\mathrm{C}\left(0.8 * Y_{1}, 0.8 * Y_{2}, 0.1 * Y_{3}, 0.1 * Y_{4}\right)+C\left(0.1 * Y_{1}, 0.1 * Y_{2}, 0.8 * Y_{3}, 0.1 * Y_{4}\right)+C\left(0.1 * Y_{1}, 0.1 * Y_{2}, 0.1 * Y_{3}, 0.8 * Y_{4}\right)-\right.$ $\left.C\left(Y_{1}, Y_{2}, Y_{3}, Y_{4}\right)\right] / C\left(Y_{1}, Y_{2}, Y_{3}, Y_{4}\right)$.

QSC TRIPLET $(\varepsilon=0.1)$, for a firm diversified in a generic triplet of outputs $\left(\mathrm{Y}_{1}, \mathrm{Y}_{2}, \mathrm{Y}_{3}\right)$, is computed as $\left[\mathrm{C}\left(0.9 * Y_{1}, 0.9 * Y_{2}, 0.9^{*} Y_{3}, 0.1 * Y_{4}\right)+C\left(0.1 * Y_{1}, 0.1 * Y_{2}, 0.1 * Y_{3}, 0.9 * Y_{4}\right)-C\left(Y_{1}, Y_{2}, Y_{3}, Y_{4}\right)\right] / C\left(Y_{1}, Y_{2}, Y_{3}, Y_{4}\right)$. 


\section{References}

Abrate G., ERBetta F. (2010) "Efficiency and Patterns of Service Mix in Airport Companies: An Input Distance Function Approach", Transportation Research Part E, 46, 693-708.

Abrate G., Erbetta, F., Fraquelli G. Vannoni D. (2014) "The Costs of Disposal and Recycling: An Application to Italian Municipal Solid Waste Services, Regional Studies, 48, 3, 896-909.

Abrate G., Erbetta, F., Fraquelli G. Vannoni D. (2016) "Bet Big on Doubles, Bet Smaller on Triples. Exploring Scope Economies in Multi-Service Passenger Transport Companies", Transport Policy, 52, 81-88.

Baumol W. J., Panzar J. C., Willig R. D. (1982) Contestable Markets and the Theory of Industry Structure, New York: Harcourt Brace Jovanovich.

BILOTKACH V. (2015) "Are Airports Engine of Economic Development? A Dynamic Panel Data Approach”, Urban Studies, 52, 9, 1577-1593.

Block H., Madden G., Savage S. J. (2001) "Economies of Scale and Scope in Australian Telecommunications", Review of Industrial Organisation, 18, 219-227.

Bloningen B., CRistea A. (2015) "Air Service and Urban Growth: Evidence from a Quasi-Natural Experiment", Journal of Urban Economics, 86, 128-146.

Bottasso A., Conti M., Piacenza M. Vannoni D. (2011) "The Appropriateness of the Poolability Assumption for Multi-Product Technologies", International Journal of Production Economics, 130, 1, 112-117.

Bottasso A., Conti M. (2012) "The Cost Structure of the UK Airport Industry", Journal of Transport Economics and Policy", 36, Part 3, 313-332.

Bottasso A., Conti M., PigA C. (2013) "Low Cost Carriers and Airport Performance: Empirical Evidence from a Panel of UK Airports", Industrial and Corporate Change", 22, 3.

Bottasso A., Bruno M., Conti M., Piga C. (2018) "Competition, Vertical Relationship and Countervailing Power in the UK Airport Industry", Journal of Regulatory Economics", Journal of Regulatory Economics", 52, 1.

Bottasso A., Conti M. (2017) "The Cost Structure of the Airport Industry: Methodological Issues and Empirical Evidence", in Bitzan J. D. and Peoples J. H. (Eds.), The Economics of Airport Operations, Volume 6, 181-212, Advances in Airline Economics, Emerald Group Publishing Limited.

Braunstein Y. M., Pulley L. B. (1998) "Economies of Scale and Scope in Telephony: Applying the Composite Cost Function to Bell System Data", in Communication and Trade: Essays in Honor of Merhoo Jussawalla, New Jersey: Hampton Press, 181-192. 
Caves D. W., Christensen L. R., Tretheway M. W. (1980) "Flexibles Cost Functions for Multiproduct Firms", Review of Economics and Statistics, 62, 477-81.

ChOw C. K. W., Fung K. Y. (2009) "Efficiencies and Scope Economies of Chinese Airports in Moving Passengers and Cargo", Journal of Air Transport Management, 15, 324-329.

Delgado M. S., Parmeter C. F., Hartarska V., Mersland R. (2015) "Should all Microfinance Institutions Mobilize Microsavings? Evidence from Economies of Scope", Empirical Economics, 48, 2, 193-225.

Di Giacomo M., Ottoz E. (2010) "The Relevance of Scale and Scope Economies in the Provision of Urban and Intercity Bus Transport", Journal of Transport Economics and Policy, 44, 2, 161-187.

FAGEDA X. (2017) "International Air Travel and FDI Flows: Evidence from Barcelona", Journal of Regional Science, 57, 5, 858-883.

GiBBONS S., WU W. (2017) "Airports, Market Access and Local Economic Performance: Evidence from China”, SERC Discussion Papers, 211.

GreENE W.H. (1997) "Econometric Analysis", third edition, Prentice Hall, New Jersey.

LIEBERT V., NIEMEIER H. M. (2013) "A Survey of Empirical Research on the Productivity and Efficiency Measurement of Airports", Journal of Transport Economics and Policy, 47, 2, 157-189.

MARTIN J. C., VOLTES-DorTA A. (2011) "The Econometric Estimation of Airports' Cost Function”, Transportation Research Part B, 45, 12-127.

Martini G., Manello A., Scotti D. (2013) "The Influence of Fleet Mix, Ownership and LCCs on Airports Technical and Environmental Efficiency", Transportation Research Part E, 50, 37-52.

MCCARTHY P. (2016) "Multi-product Cost Analysis of US Airports", in Bitzan J. D., Peoples J. H. and Wilson W. W. (Eds.), Airline Efficiency, Volume 5, 243-281, Advances in Airline Economics, Emerald Group Publishing Limited

MCELROY M. (1977) "Goodness of Fit for Seemingly Unrelated Regressions: Glahn's $R^{2}$ and Hooper's $\bar{R}^{2}$ ”, Journal of Econometrics, 6, 381-87.

MCKenZIE, D.J., SMALl, J.P. (1997) "Econometric Cost Structure Estimates for Cellular Telephony in the United States", Journal of Regulatory Economics 12, 147-157.

McKillop D. G., Glass C. J., MoriKawa Y. (1996) "The Composite Cost Function and Efficiency in Giant Japanese Banks", Journal of Banking and Finance, 20, 1651-1671.

Ottoz E., Di Giacomo M. (2012) "Diversification Strategies and Scope Economies: Evidence from a Sample of Regional Bus Transport Providers", Applied Economics, 44, 2867-2880. 
Piacenza M., Vannoni D. (2004) "Choosing Among Alternative Cost Function Specifications: An Application to Italian Multi-Utilities”, Economics Letters, 82/3, pp.410-417.

Pulley L. B., Braunstein Y. M. (1992) "A Composite Cost Function for Multiproduct Firms with an Application to Economies of Scope in Banking", Review of Economics and Statistics, 74, 221-230.

Pulley L.B., Humphrey D.B. (1993) "The Role of Fixed Costs and Cost Complementarities in Determining Scope Economies and the Cost of Narrow Banking Proposals", Journal of Business, 66 (3), 437-462.

Scotti D., Malighetti P., Martini G., Volta N. (2012) "The Impact of Airport Competition on Technical Efficiency: A Stochastic Frontier Analysis Applied to Italian Airport", Journal of Air Transport Management, 22, 9-15.

YAN D., OUM T.H. (2014) "The Effects of Government Corruption on the Efficiency of US Commercial Airports", Journal of Urban Economics, 80, 119132.

ZELlNER A. (1962) "An Efficient Method of Estimating Seemingly Unrelated Regression and Test for Aggregation Bias" Journal of the American Statistical Association, 58, 348-68. 
DEPARTMENT OF ECONOMICS AND STATISTICS

UNIVERSITY OF TORINO

Corso Unione Sovietica 218 bis - 10134 Torino (ITALY)

Web page: http://esomas.econ.unito.it/ 